\title{
Study on English Translation of Tourism Text from the Perspective of Cultural Translation Theory-A Case Study of Hailuogou
}

\author{
Jing Feng \\ Sichuan Minzu College, Kangding, Sichuan 626001
}

Keywords: English translation; tourism text; cultural translation theory

\begin{abstract}
This paper first analyzes the text types and texts of the tourism texts from vocabulary, syntax, and discourse, and then clarifies the basic requirements and principles of tourism translation. Next, in combination with the practice of tourism translation, from a cultural perspective, with the aid of typical examples of translation, the culturally specific items in the tourism text, the parallel structure, and deductions such as couplets, poetry, and colloquialism, and long sentences, etc. The translation strategies of each aspect are analyzed. Then the characteristics, requirements, principles, and techniques of English translation of tourism texts are summarized and introspected to provide some reference value for the future translation of tourism texts into English.
\end{abstract}

\section{Introduction}

As a new high-level consumer industry in the 21st century, tourism is gradually replacing the traditional first secondary industry and becoming the pillar of the national economy. As an organic combination of material and culture, tourism has become the best choice for more and more people to relax and relax. China has a rich variety of natural scenery and cultural landscapes. With the continuous development of tourism resources and the continuous escalation of tourism services, China is gradually becoming a leader in international tourism. How to further expand the international tourism market and provide better tourist services and travel experience for international tourists has become a key to the further development of China's tourism industry. Due to the diversity of historical culture, environment, religion, and political system, Chinese and Western cultures are quite different. The difference in language and culture directly leads to the lagging development of international tourism. At the same time, tourism translation should be carried out. Needless to say, cultural studies provide intellectual support and foundation for economic development [1]. Tourism translation is an important medium for the world's tourists to understand and understand China's national conditions, appreciate and experience Chinese history and culture. The quality of translated texts directly affects the wide range of tourist travel vision and the depth of tourism experience. However, at present, "travel translation, because of its particularity, diversity and complexity, is still not familiar with and mastered by our translators.

\section{Text characteristics of tourism texts}

Tourism translation is a kind of application of stylistic translation with unique language features. This section will add $\mathrm{W}$ analysis from lexical, syntactic, and discourse levels.

As tourism is a comprehensive subject and involves many fields such as economy, politics, culture, entertainment, management, consumption, and transportation, the most significant feature of tourism vocabulary is its richness. For example, the following paragraph: "Lingyin Temple is located in the northwest of Hangzhou, before the cold spring, in the face of Feilai Feng. Temple was built in the Eastern Jin Dynasty, is one of the ten Buddhist temple Buddhist Zen Buddhist temple, is the first place in the West Lake. Linzenji "The rat's forehead is a book written by Kangxi in the Qing Dynasty.... The main hall of the main hall is a single-storey Lancang Xieshan-style building. It is 33.6 meters long and its scale is huge. It is rare in China. Ghazini's argument is like the cooperation between the Zhejiang Academy of Fine Arts experts and folk artists in 1956. It was carved with 24 pieces of fragrant wood. The back of the main hall of the main hall is the colored 
facade of "May 1st H Senate". In order to accomplish the Buddhist path, Mancai Boyd, under the guidance of Manjusri Bodhisattva, visited 110 cities in the south and paid homage to 53 famous teachers. At the end, he met the Samantabhadra Bodhisattva and made it a real accomplishment. "It's not hard to find out that this is just a few hundred words. The vocabulary is extremely rich and involves a wide range of topics, including history, culture, religion, architecture and other knowledge areas. Send the request "a.translator must know something of everything and everything of something !" The translator can only be a "miscellaneous". Do it well. Of course, this is by no means a day's work. It needs to be remembered and remembered. Secondly, tourism promotional materials are mostly descriptive texts, with a four-character grid structure, exquisite use of words, and beautiful writing. Since ancient times, all the articles narrating landscape narratives have been read with fluency, and they have managed to make full use of it, giving people visual and emotional impact and spiritual enjoyment. For example, Wang Bo’s eternal masterpiece "Preface to Tengwang Ge" and Liu Zongyuan's "Little Stone" The "Tang Kee" and the "H Gap" of the toilet Tao Yuan, Wang Anshi's "You Zhuo Shan Shan Ji" and so on are all beautiful in sound, beautiful in shape, and beautiful in the imagination. One of the ultimate goals of tourism promotional materials is to allow tourists to feel and see through the text the unique natural light and cultural implication of the tourist attractions, resulting in a strong desire to watch and travel expectations. "The beauty of beauty is also available to all," and the language only allows visitors to have a good feeling so that they can "hope". Therefore, another major feature of tourism vocabulary is rhetoric and literary, which is also a major feature of Chinese language. This requires translators must have a keen sense of text and a good bilingual translation ability. W under the text is a good display of this feature: "The Qishan mountains and mountains, strange rocks, deep valleys, waterfalls, springs, ancient trees and famous wood, and the vast Yangtze River, blue wave Haoyang seamless integration A magnificent natural landscape, thousands of years ago, countless predecessors, literati, philosophers, rich politicians, have come to plunge into the embrace of this amazing mountain..... The intriguing pavilions, grand magnificent Meiyuan Temple view, exquisite towers and bridges, and Chinese and foreign villas with different styles are embedded in this wonderful mountain scenery, and are in harmony with the natural scenery. Formed a beautiful landscape with unique charm [2]."

Lushan's peaks, rocks and holes, deep valleys, waterfalls, springs, ancient and famous trees, and the vast Yangtze River, blue sea Hao Yang seamless, combined into a magnificent and natural scene. For thousands of years, countless Xian Xian Yi, scholars, visitors, Huizi Tao, rich politicians, come one after another, to devote themselves to the embrace of this wonderful mountain. The beautifully crafted pavilions, grand and spectacular Meiyuan Temple views, exquisite and wonderful tower bridge trees, and Chinese and foreign villas with different styles are embedded in this wonderful mountain scenery, and they are in harmony with the natural scenery. A beautiful landscape with unique charm. "Once again, another distinctive feature of China's tourism vocabulary is the use of quotations and quotation. There are many references to the history of poems and texts, folk idioms, etc. The marginal mountains that result in Diego's characteristics are H. One is the Chinese people's writing habits, and the other is the increase of articles. Readability, authority, and interest, $\mathrm{S}$ highlights the ornamental and humanistic atmosphere of the tourism landscape. Therefore, the Chinese travel text is full of many cultural load words, and the amount of cultural information is very large [3].

\section{Cultural Translation Concept}

Translation is an important medium for promoting interaction and interaction among different civilizations. It can "know nothing" as "everything is omniscient," and "deaf and ignorant" as "learning versatile," making a nation's history and culture grow. Continuation, shared by the people of the world. On the contrary, the constant prosperity of the culture needs to be broken, which makes translation into a "cultural envoy" with great hard work. Tourism translation allows international visitors to unknowingly experience the exotic national conditions and historical origins. It is one of the best means to spread national culture and promote the exchange of civilization. The key to cultural communication is translation [4]. The quality of translation is crucial to the translator. 
This requires that the translator must be a true cultural person. Excellent translators must be both "skilled craftsmen", have excellent and superb translation skills, and have to be a "miscellaneous family". They know that astronomy knows geography and that ancient and modern knowledge is known. Translation technicians often have it, and translators are rare. If you want to translate tastes and translate personalities, then you need to be a "cultural translator", which allows the rich accumulation of historical and humanities to give translators the "transliteration" and elegant "translations".

Compared with literary translation and technological translation, tourism translation is still a "new show" in the translation field in China. Due to the lack of systematic theory guidance and the lack of management of the translation market, there have been many mistakes in travel translation works, such as misspellings, grammatical errors, improper use of words, and expressions of praise. Among them, hate is caused by translators neglecting or despising the cultural connotation and background of tourism resources. For example, Sichuan's famous snacks "Mapo Tofu" and "Couple Lung Tablets" were translated as "化" and "lung slices" of "ecouple". What is gratifying is that in recent years, a large number of scholars have emerged in our country, correcting the phenomenon of "illiteracy" in tourism translation and advocating the study of tourism translation from the perspective of culture [5]. It emphasizes the important role of cultural transmission undertaken by tourism translation, which has substantive guiding significance for resolving cultural exports and correcting many problems in hard translation, mistranslation, etc.

\section{Conclusion}

Any translation work is not a closed one. It requires a variety of manpower, material resources, and even financial resources. When encountering difficult translation problems, it is advisable to consult colleagues and scholars. The so-called "stones from other mountains can be W attack jade, inspiration everywhere. Again, this study draws on the achievements of many previous researchers and once again expresses gratitude and thankfulness. This makes the author once again profoundly understand the powerful role of theoretical research. The lack of theoretically armed practical activities is difficult to achieve effective results; similarly, theoretical research that is out of practice is the source of dry wells and is difficult to live. The two are mutually complementary. Therefore, translators should not only pay attention to "doing" but also to "thinking".

\section{Acknowledgements}

Study on the Teaching Model Reform of the "Tourism English" Course in Universities in Ethnic Regions Project Number: 2017xjjg15.

\section{References}

[1] Yang Chunshi. System Theory Information Theory Control Theory [M]. Beijing: China Radio and TV Press, 1987.

[2] Zhang Boran, Xin Hongjuan. The theoretical bias of Western modern translation school [J]. Journal of Central South University (Social Science Edition), 2005 (4).

[3] Zhao Yanchun. Translation studies concluded that [M]. Shanghai: Shanghai Foreign Language Education Press, 2005.

[4] Zhou Zhipei Chen Yunxiang. Cultural Studies and Translation [M]. Shanghai: East China University of Technology Press, 2013.

[5] Chesterman, A. Causes, Translations, Effects[J]. Target, 1998(2) 